\title{
Los hogares de la población de nacionalidad extranjera en España en el año $2001^{1}$
}

\author{
Andreu Domingo* \\ Jordi Bayona** \\ *Universitat Autònoma de Barcelona. Centre d'Estudis Demogràfics \\ adomingo@ced.uab.es \\ **Universitat de Barcelona. Departament de Geografia Humana \\ jordibayona@ub.edu
}

Recibido: 28-04-2008

Aceptado: 27-01-2009

\section{Resumen}

El artículo se centra en el análisis de las estructuras de los hogares de la población de nacionalidad extranjera en España utilizando los datos del censo de 2001. Se muestran unas disposiciones condicionadas por la aceleración de los flujos migratorios iniciada a finales del siglo pasado, con unas estructuras más complejas que las mostradas entre el total de la población. El análisis de la estructura del hogar puede ser utilizado para comprender tanto la etapa en la que se encuentran los diferentes procesos migratorios de cada nacionalidad, como las estrategias completamente diferentes de cada una de ellas.

Palabras clave: población de nacionalidad extranjera, familia, estructura del hogar, censo de 2001, España.

Abstract. The Homes of Foreign Citizens in Spain, 2001

This article presents the analysis of household structures of the foreign population in Spain based on the 2001 Spanish Census. Due to this analysis we are able to explore structures directly related to the acceleration of the migratory flows initiated at the end of the last century, with more complex household structures among foreigners than Spaniards. Results show that the recent increase of migratory flows has modified household structures of the foreign population, which constitutes a good indicator for the status of the migration process as well as for the strategy of each of the national groups.

Key words: foreign population, family, household structure, 2001 census, Spain.

1. Este texto se inscribe dentro del proyecto de I+D Comportamientos sociodemográficos diferenciales e integración social de la población inmigrada y de sus descendientes en España (CSO2008-04778), dirigido por el Dr. Andreu Domingo y financiado por el Ministerio de Ciencia e Innovación, y el proyecto La sostenibilidad social según las formas urbanas: movilidad residencial, espacios de vida y uso del tiempo en las regiones metropolitanas (2007-2010) (SEJ2007-67948), dirigido por la Dra. Anna Alabart. 


\section{Sumario}

1. Introducción: Bajo el signo de la aceleración migratoria

2. Las estructuras del hogar donde reside la población de nacionalidad extranjera

3. Características sociodemográficas de la población según el tipo de hogar
4. De la estructura a la situación económica del hogar

5. Las estructuras del hogar y el proceso migratorio

Referencias bibliográficas

\section{Introducción: Bajo el signo de la aceleración migratoria}

Las familias y las estructuras de los hogares de las personas de nacionalidad extranjera inmigradas a España no han podido permanecer ajenas al boom migratorio experimentado durante los primeros años del siglo XXI. Los crecimientos en los flujos como los que se han dado desde el año 2000, son extraordinarios, puesto que se han multiplicado por ocho desde 1999 hasta 2006 y han implicado a más de 3,8 millones de altas durante el período. Aún asumiendo que parte de ese aumento se deba a la mejora del registro estadístico de las altas y las bajas padronales (mejor cobertura de las estadísticas de variaciones residenciales), o al efecto de visibilización de la población que anteriormente se encontraba en situación irregular, asociado a las consecutivas operaciones de regularización acaecidas desde entonces (2000, 2001 y 2005), y no al resultado de verdaderos flujos, su aceleración, traducida en el incremento de los efectivos de población residente, no deja de ser espectacular. Nos atreveríamos a afirmar que sin parangón en los países de la Unión Europea: a 1 de enero de 2007, con más de cuatro millones y medio de personas, se alcanzaba un $10 \%$ de la población empadronada, cuando al principio del siglo apenas se registraba un 3,3\%, con lo cual se ha pasado de estar por debajo de la media de la Unión Europea a ocupar el primer lugar, si exceptuamos los microestados de Luxemburgo y Liechtenstein, por delante de Austria (9,9\%) o Alemania $(8,8 \%)$, y el segundo lugar en números absolutos, sólo por detrás de Alemania (7,2 millones). El volumen, en este caso, es determinante, puesto que ha cambiado si no la naturaleza, sí la interpretación y los efectos del propio fenómeno observado, empezando por su contribución al crecimiento de la población durante el período 2000-2005, en el que el 94\% se debe exclusivamente al saldo migratorio, pero continuando con su significativa participación en otros fenómenos demográficos elementales, especialmente los nacimientos y la fecundidad (Fernández Cordón, 2006) o la propia movilidad interna en España (Recaño, 2002 y 2004). Como hemos dicho, la dinámica familiar y los hogares también se verán afectados por ello.

Los trabajos clásicos sobre el papel de las redes sociales en los procesos migratorios (Portes y Börözc, 1982), así como los estudios para el caso español, atendiendo a la evolución reciente de la migración internacional (Camarero y García, 2004; Aparicio y Tornos, 2005; Pascual de Sans, 2007), ponen de 
manifiesto la centralidad de la familia en la constitución de las corrientes migratorias. Centralidad que se despliega en la gestación del proyecto de movilidad como producto de la estrategia del propio núcleo familiar, del mismo modo que en la ayuda recibida por los parientes más o menos cercanos gracias a las redes que se establecen una vez los inmigrantes han llegado al país de destino.

Los estudios sobre familia y migración suelen fijarse en los procesos más que en las estructuras, ya sea en la formación de nuevas familias o en el reagrupamiento familiar. En el primer caso, la dinámica familiar puede producirse tanto en el país de acogida como en el país de origen, lo cual revela la existencia de mercados matrimoniales transnacionales o la apertura o intersección con el mercado matrimonial del lugar de acogida, lo cual da lugar a lo que algunos califican de matrimonios mixtos. En todo caso, nupcialidad y fecundidad son los dos fenómenos demográficos más estudiados en referencia a la dinámica familiar de la población inmigrada, sin casi dar importancia por el momento a las disoluciones, sea por mortalidad o por ruptura de la unión, situación también comprensible debido al reducido número de inmigrantes hasta fecha reciente. De todos los posibles fenómenos, si el análisis de los matrimonios ha sido un campo tradicionalmente abordado por la antropología (ver Rodríguez, 2004 y 2006), y aunque en los últimos años han empezado a publicarse contribuciones desde la demografía (Cortina, Esteve y Domingo, 2006 y 2008), en ésta última es la fecundidad, sin lugar a dudas, la que más expectativas ha generado, por muchas razones, pero quizás la principal haya sido por dilucidar la contribución de la fecundidad de las extranjeras en un país como España, caracterizado por niveles inusualmente bajos (Devolder y otros, 2003; Izquierdo y López de Lera, 2003; Delgado y Zamora, 2004; Izquierdo Escribano, 2006; Del Rey Poveda y Ortega Osona, 2007; Roig y Castro, 2007). Por otro lado, el reagrupamiento familiar, que debe considerarse una parte importante y específica de la dinámica de los inmigrantes, depende claramente del volumen de los flujos y de la maduración de los procesos migratorios. Quizás su característica más relevante es la implicación de diferentes generaciones (Jasso y Rosenzweig, 1986). Si, en un principio, lo habitual es asistir a la reagrupación de coetáneos generacionales o de generaciones más jóvenes (correspondientes a cónyuges y descendencia), con el tiempo, no es inusual la reagrupación de ascendientes. Claro está que la legislación limita y determina tanto la posibilidad de esas reagrupaciones como sus condiciones (incluyendo la reagrupación en situación irregular). El examen de este último e importantísimo fenómeno es, pues, complejo y, desafortunadamente, como en otros aspectos de la inmigración internacional, de difícil comparación entre los diferentes países de la Unión Europea, puesto que ni la definición de familiar ni los requisitos que se exigen son los mismos en cada país (Salt, 2005). Su relativa novedad en España, pero sobre todo la dificultad para obtener los datos estadísticos, explican que, por el momento, las aproximaciones demográficas sean indirectas y muy escasas (Devolder, Domingo y García, 2003; Bledsoe, 2006).

$\mathrm{El}$ análisis demográfico de las estructuras del hogar ha sido mucho menos frecuente que el de las dinámicas, en parte también por las dificultades de su 
registro y por lo relativamente reciente de la inmigración internacional, como apuntábamos en el caso del estudio de la ruptura de uniones o de las reagrupaciones, aunque, para algunas comunidades autónomas, la estadística de población anexa al padrón de 1996 ya permitía realizar ese análisis (Domingo, Bayona y Brancós, 2002). La observación de las estructuras del hogar a través de los datos censales recuerda vagamente a la contemplación de estratos geológicos. La sección del momento nos brinda una imagen estática de lo que, por definición, es móvil: la evolución de las estructuras de los hogares incluye tanto la dinámica familiar como los avatares biográficos de los individuos que la componen y que sin duda se encuentran también influidas por la coyuntura, empezando por la económica. Si eso es cierto para el conjunto de la población, en el caso de la población extranjera, además, frecuentemente se registra con mayor fidelidad las etapas del ciclo migratorio que las propias formas familiares y, por ende, no sólo las estrategias migratorias, sino también los accidentes puntuales que dichas corrientes experimentan, lo cual no ayuda a interpretar los procesos de asentamiento de la población inmigrada. En este sentido, la aceleración y las transformaciones de las corrientes migratorias internacionales dirigidas a España, tanto en su diversificación por orígenes como en la propia estructura sociodemográfica, durante los últimos años del siglo XX y los primeros del siglo XXI, son de una tal magnitud que no creo exagerar si las calificamos de realmente excepcionales. El censo, ya en noviembre de 2001, va a captar el ascenso de los flujos procedentes de Latinoamérica, que acabarán por convertir a los ciudadanos latinoamericanos en los protagonistas indiscutibles de ese boom, puesto que preceden el incremento de los migrantes de los países del Este de Europa (Izquierdo Escribano, López de Lera, Martínez Buján, 2002; Domingo, 2006). El censo de 2001, que constituye aquí la principal herramienta estadística de la que nos vamos a valer, fija y reproduce ese prodigioso cambio, lo cual nos permite relacionar las características de los individuos con la de los hogares que forman y el de las viviendas que ocupan. A nadie se le oculta las repercusiones que las familias y los hogares de población de nacionalidad extranjera tienen sobre el mercado de trabajo, la educación, la sanidad o la vivienda de un territorio determinado, realidad que justifica ampliamente que nos dediquemos a su análisis, continuando trabajos anteriores (Domingo y Parnau, 2007; Bayona, 2007).

\section{Las estructuras del hogar donde reside la población de nacionalidad extranjera}

Antes de describir la tipología de las estructuras de los hogares, resulta conveniente considerar algunos aspectos metodológicos sobre la clasificación adoptada por el Instituto Nacional de Estadística y el uso que aquí se ha hecho de la misma. La metodología utilizada por el INE para establecer la tipología de hogares seguida en el censo de 2001 parte de la clasificación propuesta por Peter Laslett (1972) en función de la identificación y la cuantificación de los núcleos familiares y de la presencia o ausencia de otras personas que residen 
en una vivienda común. En la misma, se entiende por núcleo familiar una concepción restringida de la familia a los lazos más estrechos de alianza y filiación. Entre los primeros, se considera a las parejas (con o sin hijos, siempre que estos no convivan con su propia pareja en el mismo hogar) y, entre los segundos, a los núcleos monoparentales (padre o madre con su descendencia, con las idénticas restricciones respecto a los hijos que en el caso anterior). A partir de la distinción de núcleos y de la discriminación entre familiares y no familiares para el resto de personas que forman el hogar, se ha construido una tipología con cinco grandes grupos de hogares (que no coincide con la adoptada en censos anteriores o por otros institutos de estadística de las comunidades autónomas, pero que, de ordinario, permite reordenarlos de forma coincidente) $)^{2}$.

A pesar de que la clasificación del INE tiene la ventaja de priorizar el vínculo de parentesco de cada hogar y permite de entrada identificar a los hogares familiares (en sentido amplio, todas las relaciones, tanto las de consanguinidad como las de alianza) y los no familiares (en sentido estricto), en el análisis y la presentación de los resultados, hemos decidido, sin embargo, dar más relevancia a la existencia de núcleo familiar y al tipo de núcleo (pareja o monoparentalidad) que a la relación de parentesco de las personas que conviven juntas. Dos son las principales razones para haber tomado esta decisión: en primer lugar, creemos que, en general, la distinción entre tipo de núcleo es más informativa sobre las características y las necesidades del hogar que la discriminación entre grupos familiares o no familiares, y, en segundo lugar, específicamente para los extranjeros, el establecimiento y la discriminación de los núcleos, en una primera aproximación, es mucho más reveladora del proceso de asentamiento, aunque la determinación de los vínculos familiares sea también obligada para entender las estrategias familiares en las redes y los procesos migratorios. De este modo, nuestra reorganización contempla también cinco grandes tipos de hogar: 1) hogares unipersonales, que son aquellos donde vive una sola persona; 2) hogares sin núcleo, formados por dos personas o más, que pueden estar emparentadas o no pero que no constituyen núcleo familiar; 3) hogares formados por parejas, donde se agrupan los hogares nucleares simples, integrados por parejas con o sin hijos, en ausencia de otras personas, y los comple-

2. La clasificación del INE distingue estos cinco grandes grupos: 1) hogares unipersonales, que son aquellos constituidos por una sola persona; 2) hogares multipersonales que no forman familia, compuestos por dos o más personas que no están emparentadas de ninguna manera; 3) una familia sin otras personas, que comprende los hogares nucleares simples, integrados por un núcleo familiar en ausencia de otras personas, más los hogares donde viven personas emparentadas que no forman núcleo familiar sin otras personas; 4) una familia con otras personas no emparentadas, que engloba a los hogares nucleares complejos, compuestos por el núcleo familiar en presencia de otras personas, más los hogares donde viven personas emparentadas que no forman núcleo familiar más otras personas sin relación de parentesco, junto con los hogares múltiples, es decir, aquellos en los que existe más de un núcleo familiar que convive o no con otras personas, y 5) dos o más familias sin otras personas, es decir, excluyendo los núcleos familiares. 
jos, donde, además de la pareja con o sin hijos, residen otras personas (indistintamente de si son familiares o no); 4) hogares monoparentales, donde residen núcleos familiares de padre o madre y descendientes, con o sin otras personas (independientemente de que sean familiares), y 5) hogares múltiples, donde encontramos más de un núcleo familiar.

En el presente apartado, se analizará la tipología de los hogares y se dejará para los siguientes las características de las personas que viven en cada tipo de ellos. En uno y otro caso, se comparan siempre aquellos hogares donde, por lo menos, reside una persona de nacionalidad extranjera, con los hogares y la población que los forman para el total de la población. Si bien se hace una aproximación general para el conjunto de extranjeros, se ha decidido desestimar las grandes agrupaciones continentales, ya que la heterogeneidad de las nacionalidades que esconde este tipo de agrupación, hoy por hoy, resta sentido al agregado, sobre todo en una materia tan particular como la estructura del hogar. Aún a este respecto, queremos señalar que la muestra del $5 \%$ censal disponible ha impuesto también ciertas limitaciones al análisis por nacionalidades.

Como podemos observar en la tabla 1, según el censo de 2001, en España había poco más de 14 millones de hogares con un promedio de 2,9 personas por hogar. De 677.449 de ellos por lo menos formaba parte un extranjero (4,8\% del total), y el promedio era mayor, con 3,3 personas por hogar. Estos últimos hogares, un poco más de la mitad, el 54\%, estaban formados tan sólo por personas de nacionalidad extranjera, con un promedio de 2,7 miembros en cada hogar. En los 311.945 restantes, convivían personas de nacionalidad española y extranjera. En este caso, los hogares eran de mayor dimensión, puesto que alcanzaban las 3,9 personas por cada uno (la presencia desigual de los hogares unipersonales en una u otra categoría está en el origen de las diferencias en el tamaño entre hogares donde todos son extranjeros y hogares con españoles y extranjeros). En conjunto, en los hogares con extranjeros residían más de 2,2 millones de personas, un 30\% de las cuales tenían nacionalidad española.

El tipo de hogar predominante, independientemente de la nacionalidad de sus miembros, era el formado por parejas, que significaba el $62,9 \%$ de todos, y el $49,7 \%$ de los hogares donde residía por lo menos una persona de nacionalidad extranjera. Tras los hogares formados por parejas, para la población extranjera, los hogares sin núcleo y los unipersonales eran los más representados, puesto que llegaban al 19,1\% y al 18,8\% del total, seguidos por los monoparentales $(8,2 \%)$ y los múltiples $(4,2 \%)$. El número reducido de hogares no familiares, unipersonales y sin núcleo (además de los monoparentales) seguía siendo también una de las características de la estructura del hogar en España respecto a otros países europeos, pese a que, en los últimos años, hubieran crecido de forma significativa (Requena, 2001), hecho por el cual aún contrasta más el diferente peso proporcional para el total de la población y para los extranjeros, en tipos de hogar como los unipersonales o los sin núcleo (que para el total se reduce a un $4,5 \%$ ). 


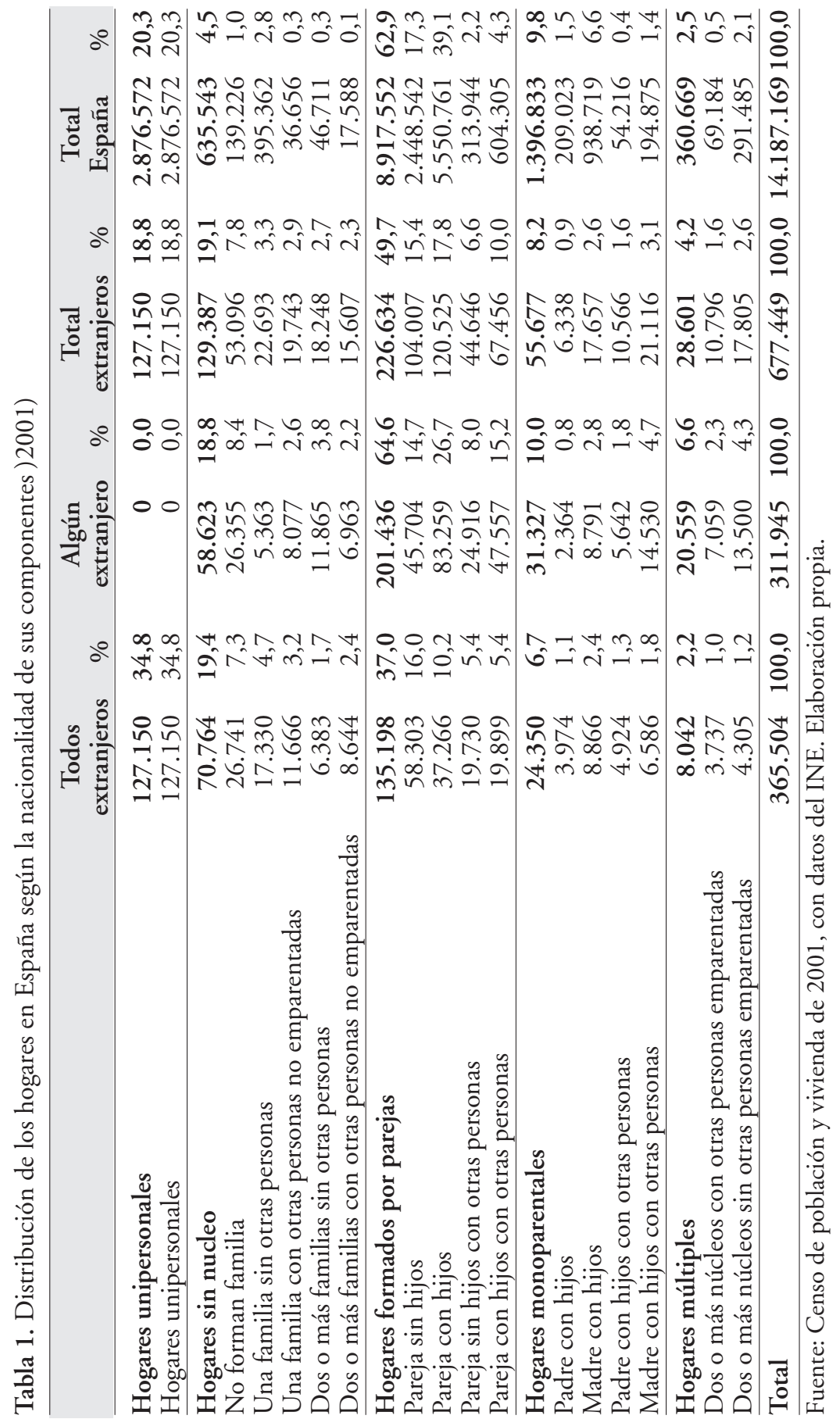


Un segundo aspecto a destacar entre las viviendas con población extranjera es el peso superior de los llamados hogares complejos (los formados por parejas o monoparentales, cuando, además del núcleo familiar, residen en él otras personas, estén o no emparentadas). En este caso, la presencia de hogares complejos entre los extranjeros triplica a la del total $(21,3 \%$ y $8,3 \%$, respectivamente), lo cual evidencia la mayor complejidad residencial y la presencia de redes de apoyo en el acceso a la vivienda.

Por nacionalidades, como puede apreciarse en el gráfico 1, el carácter económico y el impacto de los últimos flujos procedentes de países extracomunitarios se traduce en la importancia que adquieren los hogares sin núcleo. Entre las viviendas donde encontramos ecuatorianos, senegaleses y pakistaníes, las que no tenían núcleo superaban incluso a las formadas por parejas. Estas dos últimas nacionalidades llegaban a sobrepasar la mitad de todos los hogares (representaban el 51,6 y el 58,4\%, respectivamente), mientras que para los hogares donde residían británicos, por ejemplo, tan sólo agrupaban al 10,2\% (cifra que, por su lado, dobla la presentada por el total de hogares).

En segundo lugar, la presencia de otras personas alrededor de los núcleos familiares se demuestra claramente discriminante. De este modo, una vez más, a excepción de los británicos, para el resto de nacionalidades cuando vivían en parejas con o sin hijos, más de la mitad de los hogares de este tipo resultaban ser complejos, es decir, que también se integraban en ellos otras personas además de la pareja.

En tercer lugar, es de destacar el carácter eminentemente familiar de las redes migratorias, que puede inducirse del número de hogares con más de una persona, donde por lo menos había dos que declaraban tener vínculos familiares, aparte de los que consideramos núcleo familiar, que era del $87,9 \%$. Incluso en los hogares sin núcleo, aquellos formados por personas emparentadas o donde como mínimo dos personas lo estaban, era siempre superior al de personas sin ningún vínculo de parentesco, casi el $80 \%$ de los hogares sin núcleo que contenían senegaleses, o el $66 \%$ con pakistaníes, pero también en el $60 \%$ de los formados por ciudadanos británicos.

Por último, en cuarto lugar, y como veremos de forma más clara teniendo en cuenta la composición por sexo y edad de la población por nacionalidad que reside en hogares monoparentales, a excepción de la británica, este tipo de hogares tenía mucho más que ver con las estrategias migratorias predominantes entre los ciudadanos de cada una de las nacionalidades consideradas que con la disolución de una pareja o el envejecimiento de la población, como sucede en el caso de la población no inmigrada o en el total de la española (ver gráfico 3). Desde este punto de vista, no es sorprendente constatar como, para los colectivos que se caracterizan por un desequilibrio favorable a los hombres, como los de nacionalidad senegalesa, pakistaní o marroquí, el número de hogares monoparentales formados por padres con hijos sea muy superior al formado por madres con hijos. Ese desequilibrio que desvela una etapa, que presumimos temprana, del proceso migratorio con el establecimiento de hogares formados por padres e hijos de sexo masculino (a este respecto equiparables a 


\section{Ecuador}

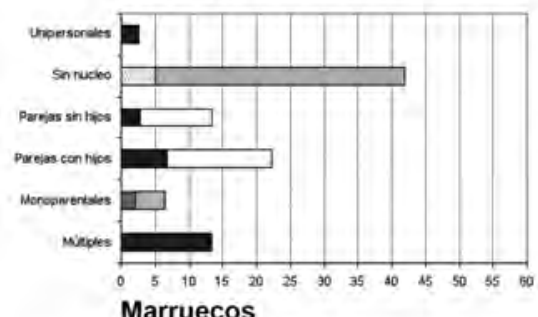

Marruecos

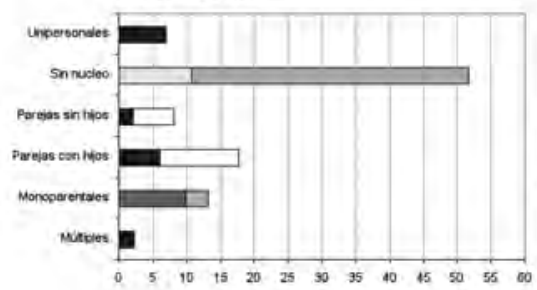

Reino Unido

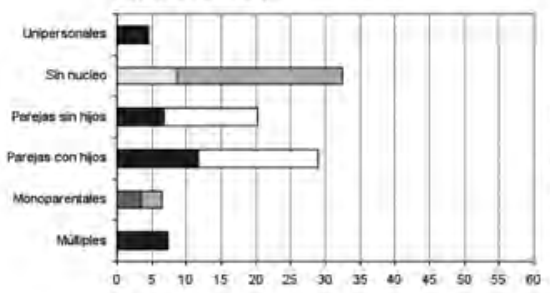

China

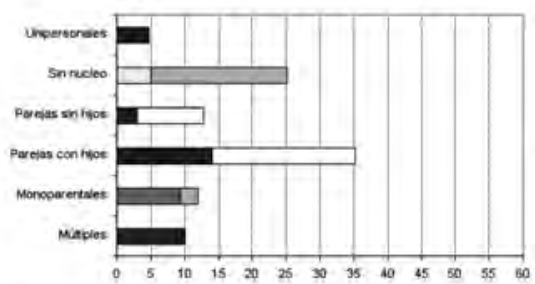

Colombia
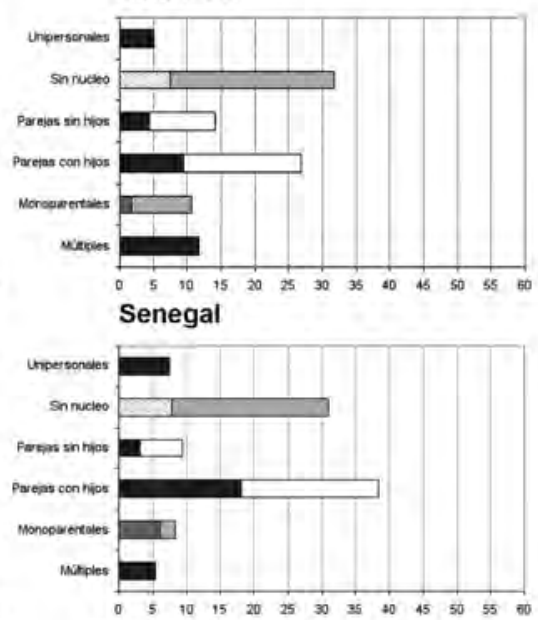

Rumanía

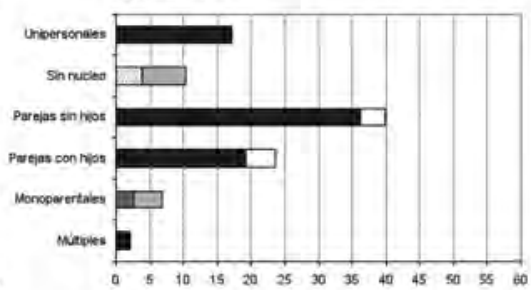

Pakistán

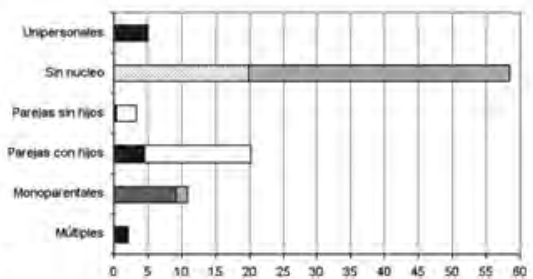

Sin otras personas $\square$ Con otras personas $\square$ Padres $\square$ Madres $\boxminus$ No emparentados $\square$ Algún emparen tado

Gráfico 1. Distribución de los tipos de hogar en España, según la nacionalidad de sus componentes (2001). Fuente: Censo de población y vivienda, 2001, con datos del INE. Elaboración propia.

los hogares sin núcleo), está también presente en otras nacionalidades cuya población en conjunto no registra grandes desigualdades en los efectivos por sexo, como, por ejemplo, la china.

En el polo opuesto, encontramos a colombianos o ecuatorianos, en cuyos colectivos las mujeres han sido las protagonistas de los flujos migratorios, con 

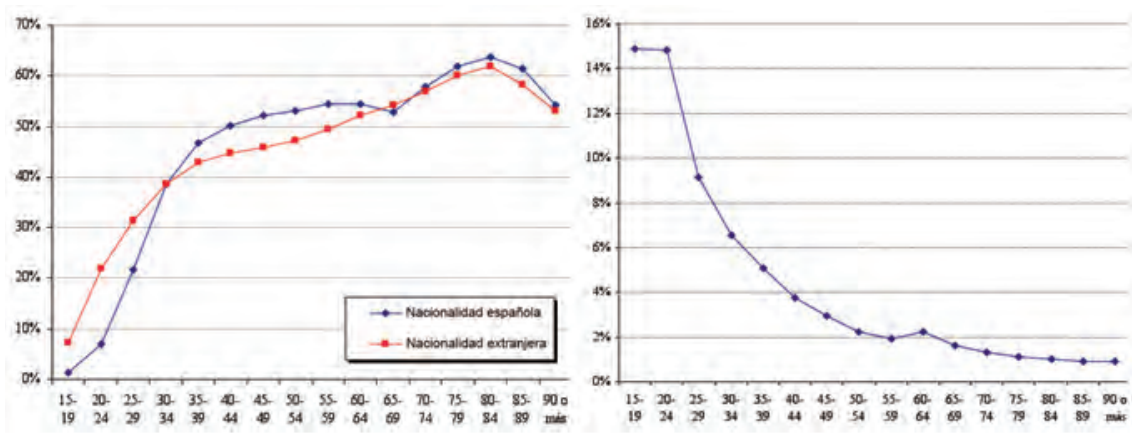

Gráfico 2. Tasa de personas de referencia del hogar, por nacionalidad y edad, y proporción de hogares con persona de referencia extranjera por edad (2001). Fuente: Censo de población y vivienda, 2001, con datos del INE. Elaboración propia.

unos hogares monoparentales formados por madres e hijas que son siempre mucho más numerosos que los compuestos por padres e hijos, pero, como veremos más adelante, también en este caso la lógica migratoria se impone a la disolución de familias y al efecto del envejecimiento sobre la dinámica familiar. Aunque es de esperar que, con el asentamiento de población inmigrada, este tipo de hogar tienda a reflejar más el resultado de las disoluciones familiares que el proceso migratorio, aún no es así. En cuanto a la formación de hogares monoparentales que se expliquen por el proceso de envejecimiento de la población o en el caso de los inmigrados extranjeros, también por la reagrupación de personas mayores, resulta más difícil predecir su evolución por nacionalidades.

Finalmente, y como se observa en el gráfico 2, la proporción de personas de referencia del hogar es inferior entre los extranjeros, como se desprende del mayor tamaño del hogar cuando en éste se encuentra un extranjero. Por edad, en cambio, se observa una mayor proporción de personas de referencia entre las edades más jóvenes, fruto de la mayor independencia domiciliar como consecuencia del propio proceso migratorio y del retraso en la emancipación de los españoles. De esta forma, en algunos de los grupos de edades más jóvenes, los hogares con personas de referencia extranjera llegan a representar aproximadamente un $15 \%$ de los existentes.

\section{Características sociodemográficas de la población según el tipo de hogar}

Desde la perspectiva de los individuos, nuestra comprensión de las formas de convivencia puede ser completamente diferente a la que obtenemos partiendo de los hogares (King y Preston, 1990; Requena, 2001, 2005 y 2006). Eso también es cierto en el caso de la población de nacionalidad extranjera. Así, pese a que, como hemos visto, los hogares unipersonales representan casi el $19 \%$ de todos los hogares donde por lo menos uno de sus miembros es de nacionalidad extranjera, solamente el $8 \%$ de la población extranjera vive en 


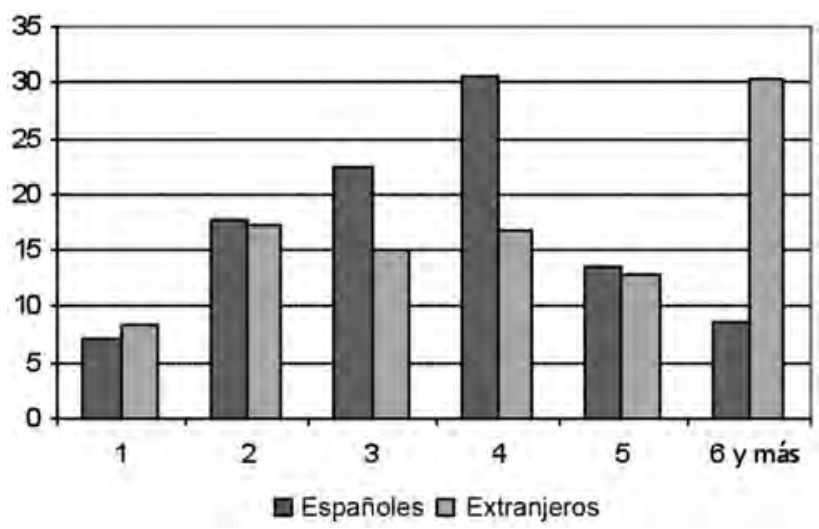

Gráfico 3. Distribución porcentual de la población por tamaño del hogar, tanto en el caso de españoles como de extranjeros (2001). Fuente: Censo de población y vivienda, 2001, con datos del INE. Elaboración propia.

este tipo de hogar. Pero más allá de la simple distribución, son las características sociodemográficas de la población que forma cada tipo de hogar las que revelan naturalezas muy dispares entre aquéllos integrados por personas de nacionalidad española y los que lo están por personas de nacionalidad extranjera o de ambas nacionalidades, aunque la morfología sea similar.

Las diferencias entre la distribución de la población de nacionalidad española y la de nacionalidad extranjera es notable empezando por la distribución de los individuos según el tamaño del hogar (ver gráfico 3). Mientras que el $30 \%$ de los españoles se ubica en hogares compuestos por cuatro personas y casi la mitad en hogares de tres o menos (47\%), el 30\% de los extranjeros forma parte de hogares con seis o más personas, y más de la mitad vive en uno de más de tres personas (59\%). Esa distribución sesgada a favor de los hogares con mayor número de miembros es aún más impresionante si la consideramos para las nacionalidades seleccionadas (ver gráfico 4): a excepción del Reino Unido - el 45\% de los británicos forma hogares de dos sujetos, y tan solo el $4 \%$ de 6 o más-, las personas que residen en hogares con más de seis integrantes representan siempre el porcentaje más elevado. La horquilla se sitúa entre el mínimo $36,4 \%$ de los rumanos y el máximo 57,2\% de los ecuatorianos. La mayor parte de los individuos de las diferentes nacionalidades consideradas que convive con cinco o más personas lo está haciendo en hogares sin núcleo o complejos, especialmente los que registran la presencia de parejas con hijos. Entre la población colombiana y ecuatoriana que vive en hogares de más de seis miembros, el porcentaje de las personas que lo hacen en hogares múltiples (con más de un núcleo) es incluso superior al de las que lo hacen en hogares complejos formados por una pareja y otras personas.

El peso de los hogares muy numerosos tiene su clara repercusión en el promedio de personas que habitan en cada uno, pero también está directamente 


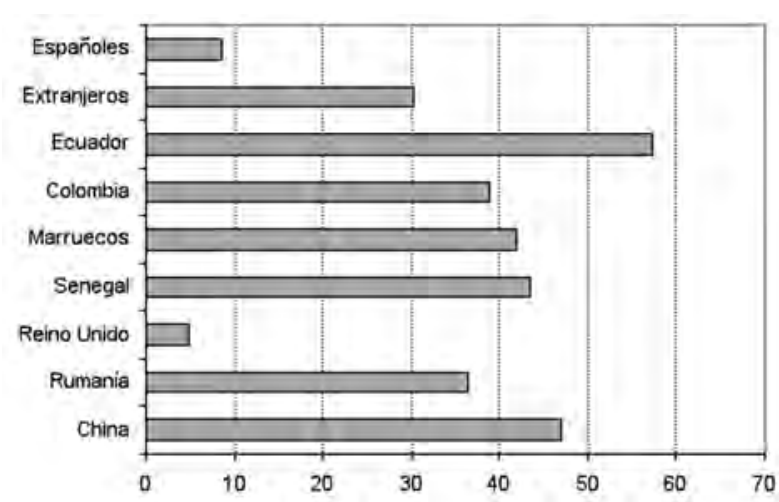

Gráfico 4. Proporción de personas que viven en hogares de seis y más personas por nacionalidades, comparando también la media de españoles y extranjeros (2001). Fuente: Censo de población y vivienda, 2001, con datos del INE. Elaboración propia.

relacionado con las características de la vivienda y, en definitiva, con un indicador de la calidad de vida de los hogares de diferentes nacionalidades. De este modo, si observamos la superficie en metros cuadrados por persona según el tamaño de la vivienda y la nacionalidad, encontramos que, para el total de extranjeros, éste se reduce a $18 \mathrm{~m}^{2}$, mientras que para los españoles se sitúa en $26,1 \mathrm{~m}^{2}$. Entre las nacionalidades analizadas, en un extremo encontramos a los ciudadanos del Reino Unido, con $37,8 \mathrm{~m}^{2}$ por persona (el promedio para todos los residentes de la Unión Europea es de 33,6 $\mathrm{m}^{2}$ ), mientras que en el opuesto se halla el Pakistán, con $11,9 \mathrm{~m}^{2}$. Recordemos que esta nacionalidad es la que más proporción de individuos registra viviendo en hogares de seis y más personas y que ello estaba también relacionado con el elevadísimo número de hogares sin núcleo. El resto de nacionalidades se mueve entre los $12 \mathrm{~m}^{2}$ de Ecuador y los $15,9 \mathrm{~m}^{2}$ de Rumania, aunque debemos tener en cuenta que dicha densidad también viene determinada por la distribución espacial de la población extranjera en España, en especial para nacionalidades con altas concentraciones en las ciudades.

Con todo, la distribución de la población por tipo de hogar para el total de los extranjeros, al contrario de lo que sucede con el total de la población, no difiere excesivamente de lo que hemos observado con la distribución de los hogares: casi la mitad del millón y medio de personas extranjeras censadas en 2001 se encontraba en viviendas formadas por parejas, el 49,4\% (un poco más las mujeres, ver tabla 2), aunque éstas sólo representen el 2,5\% del total de personas que integran este tipo de hogar en España. Como particularidad frente a la distribución del total de censados, destaca la proporción de personas que se integran en hogares sin núcleo, 26,6\%, frente al escaso 4,9\% del total o el 7,1\% de extranjeros en hogares múltiples frente al 5,1\% del total. En el polo opuesto, encontramos la concentración del total de población en los hogares formados por parejas que alcanzaba el $74 \%$. 


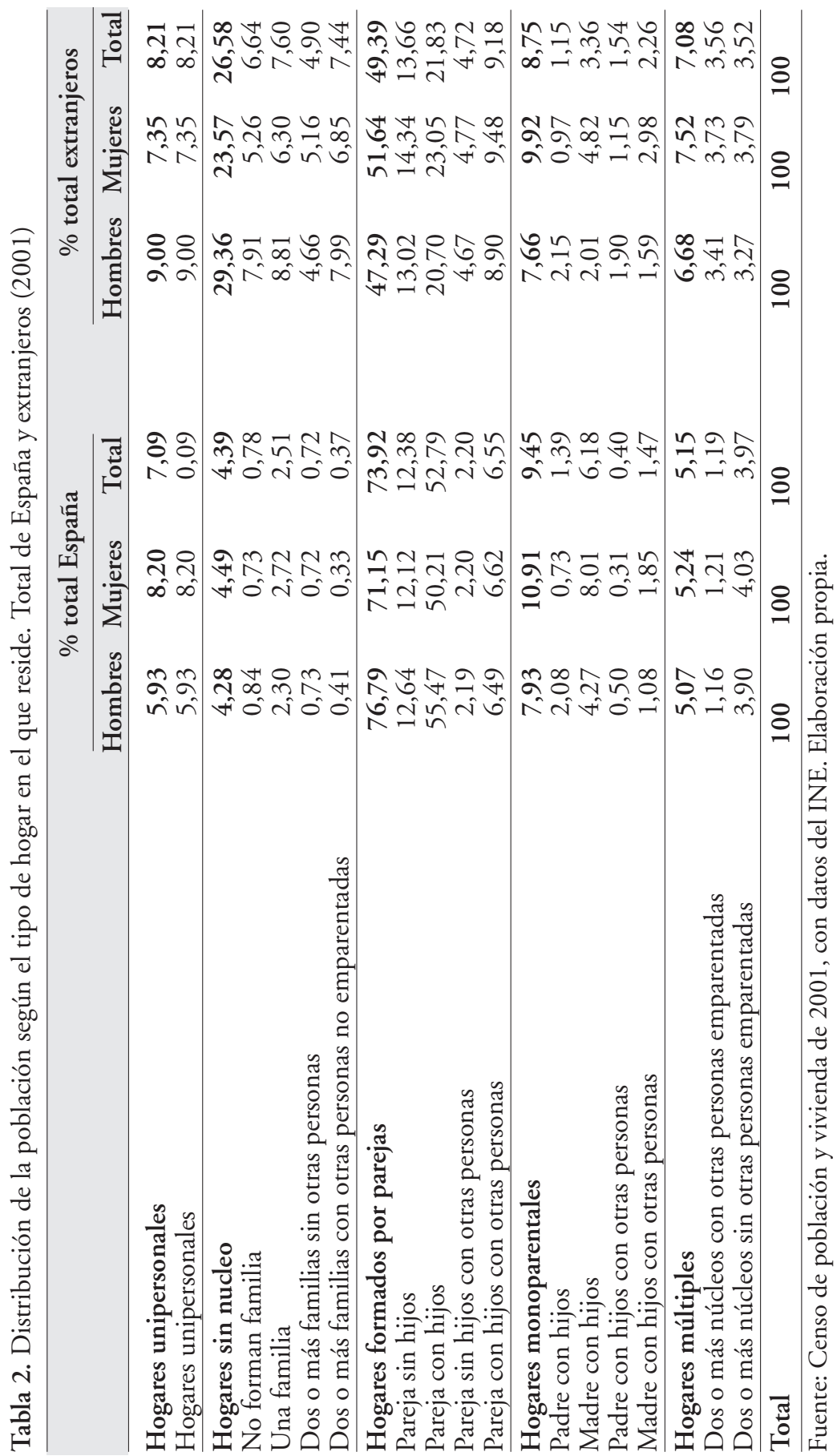


Las diferencias entre la distribución según el tipo de hogar del total de la población y la población de nacionalidad extranjera ponen de manifiesto la distancia que media entre una estructura que refleja casi exclusivamente el ciclo de vida y una estructura afectada por el proceso migratorio, aún teniendo en cuenta que seguimos considerando la heterogénea amalgama que significa el conjunto de la población extranjera.

De esta forma, si se observa la evolución por tipo de hogar en función de la edad (ver gráfico 5), se aprecian mayores diferencias. Por ejemplo, el 80\% de los menores de edad en la población total está viviendo en hogares formados por parejas con hijos, mientras que la población extranjera reduce ese porcentaje por debajo del $60 \%$, en favor sobre todo de los hogares sin núcleo y los hogares múltiples. Del mismo modo, mientras del perfil bimodal del total de la población que forma parte de hogares con parejas e hijos es fácil deducir un patrón de emancipación familiar, por cierto singularmente tardía, entre la población de nacionalidad extranjera ese patrón bimodal muestra una inflexión anterior y un perfil mucho más joven que concuerda con la definición diversa del período de juventud entre migrantes y autóctonos (Domingo, Bayona y Brancós, 2002). Nótese, por ejemplo, que el porcentaje de personas de nacionalidad extranjera entre 20 y 24 años que viven como parejas sin hijos alcanza el 15,8\%, mientras que entre los españoles únicamente se registran el 4,2\%. Pero, una vez más, es el porcentaje de población a diferentes edades que forman parte de hogares sin núcleo y unipersonales lo que llama más la atención por sus radicales variaciones por nacionalidad: el envejecimiento de la población y la feminización son la pauta de la población española, con un máximo del 12,5\% en los hogares sin núcleo a los 90 y más años, de los que un $82,6 \%$ son mujeres; mientras que la juventud y la masculinización lo son para los extranjeros, con un máximo de $35,7 \%$ entre los 25 y los 29 años, de los que un $62 \%$ son hombres. Como es de suponer, el signo en el sexo debería matizarse o exagerarse si lo analizamos nacionalidad por nacionalidad, escorándose en la dirección del desequilibrio por sexos imperante en cada uno de ellos. Eso es aún más evidente si se observan las pirámides de población por nacionalidad que vive en cada uno de esos tipos de hogar (gráfico 7).

Estas diferencias en la edad y el tipo de hogar donde residen se trasladan también a la posición dentro del mismo (ver gráfico 6). Para la población de nacionalidad española, en prácticamente el $90 \%$ de los casos se forma parte directa del núcleo familiar (persona de referencia, cónyuge o pareja, e hijo de éstos), y esta proporción disminuye a partir de los sesenta años. Para los extranjeros, en cambio, existe una alta proporción de personas que residen en el hogar sin formar parte directa del núcleo, ya estén o no emparentados con él, y que en los 20-24 años es incluso la situación más común. Al mismo tiempo, entre las edades correspondientes a los jóvenes es donde las diferencias son más acusadas, un 76,5\% de ellos con 15-29 años en España se encuentran como hijos en el hogar, porcentaje únicamente del 16\% entre los jóvenes con nacionalidad extranjera. 


\section{Españoles}

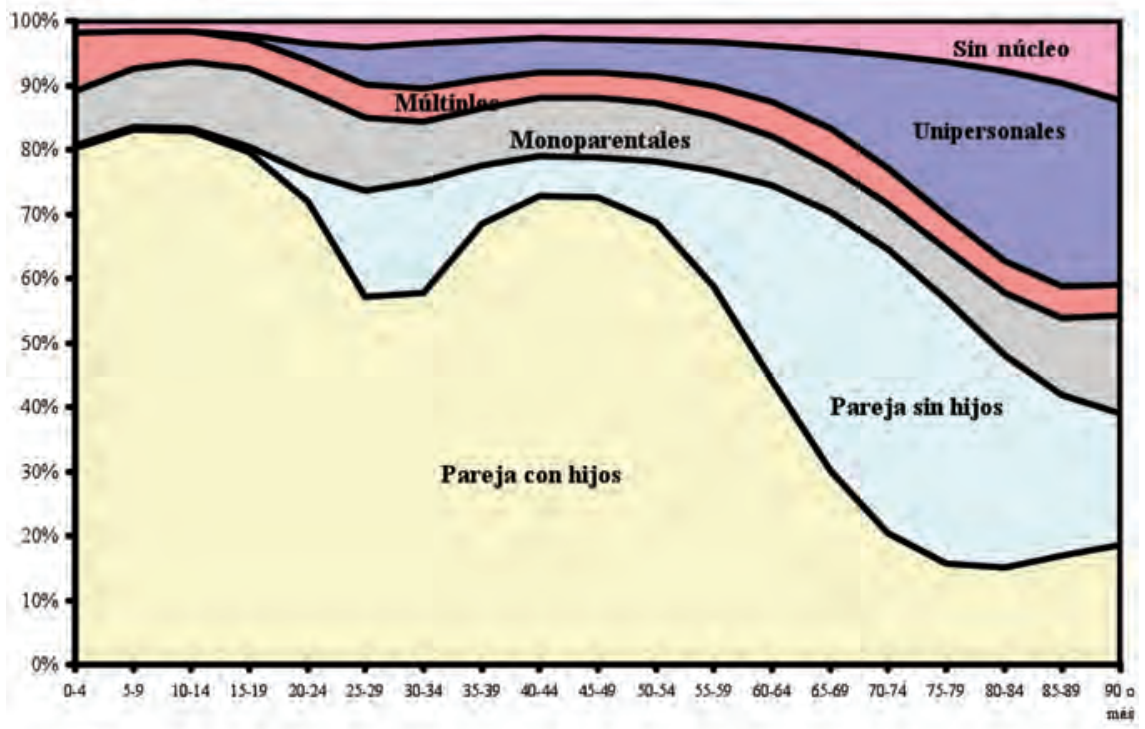

\section{Extranjeros}

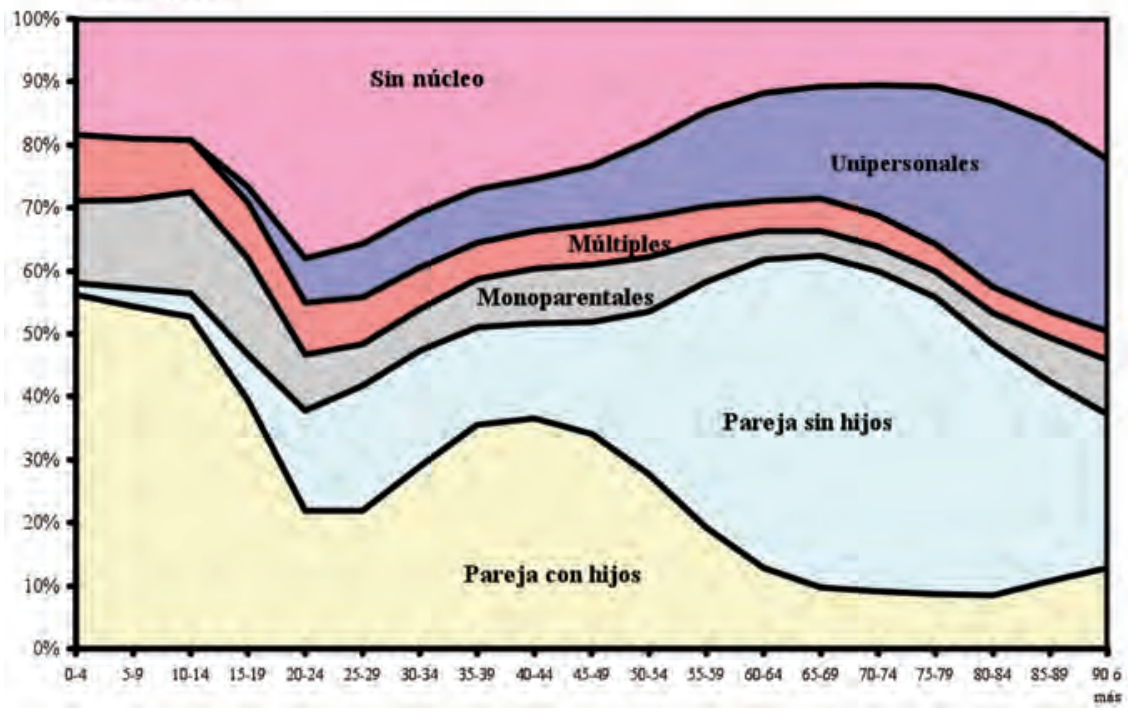

Gráfico 5. Distribución de la población según el tipo de hogar en el que reside. Españoles y extranjeros (2001). Fuente: Censo de población y vivienda, 2001, con datos del INE. Elaboración propia. 


\section{Españoles}

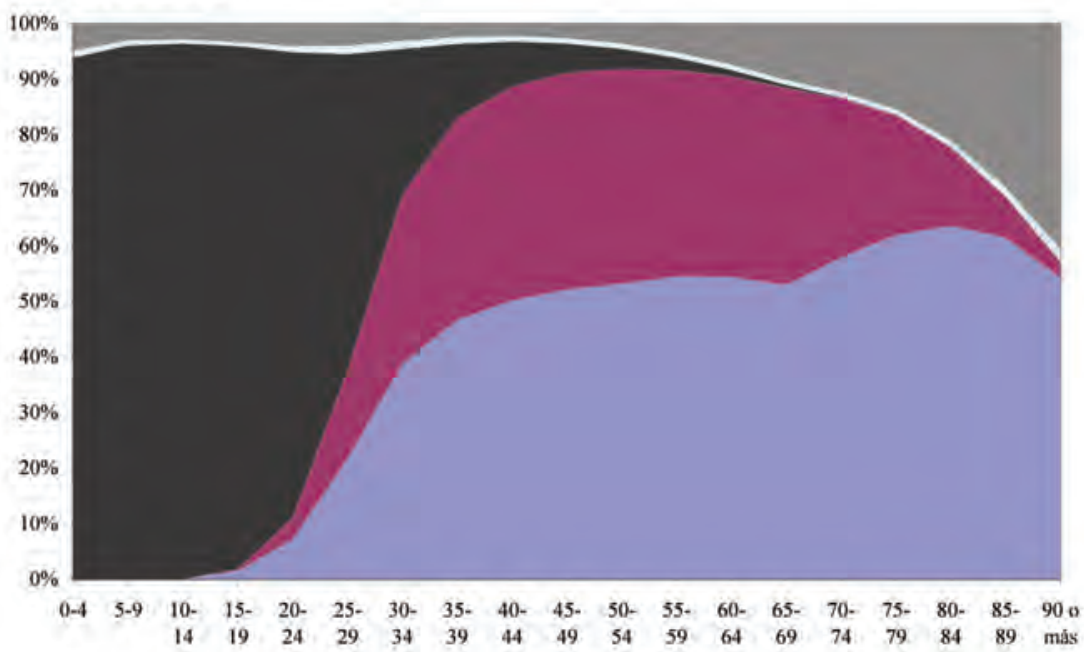

\section{Extranjeros}

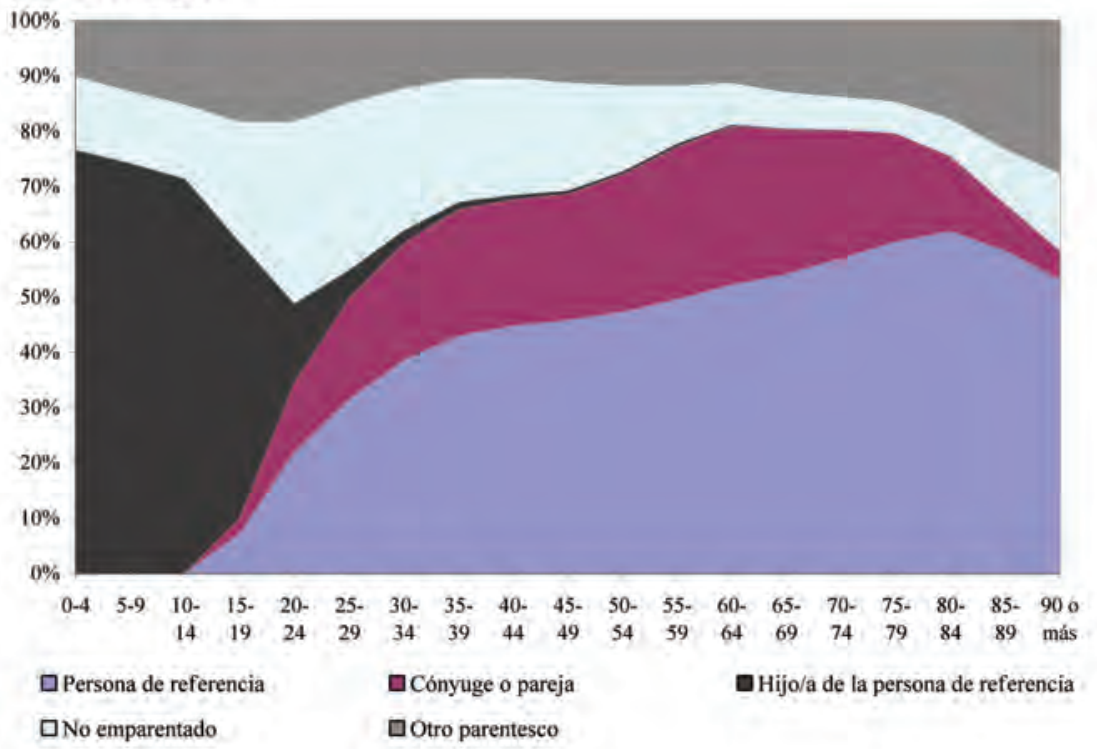

Gráfico 6. Distribución de la población según la nacionalidad, la edad y la relación con la persona de referencia del hogar (2001). Fuente: Censo de población y vivienda, 2001, con datos del INE. Elaboración propia. 


\section{Hogares unipersonales}

Extranjeros

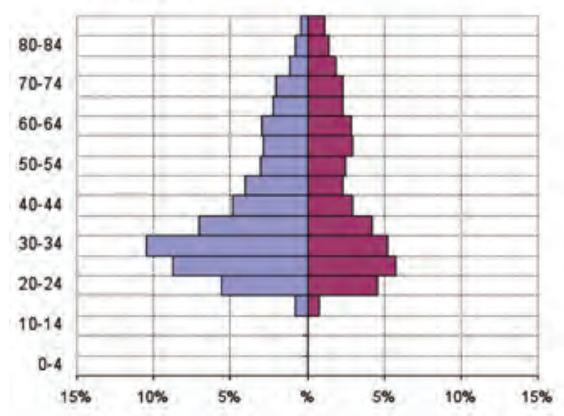

\section{Hogares sin núcleo}

Extranjeros

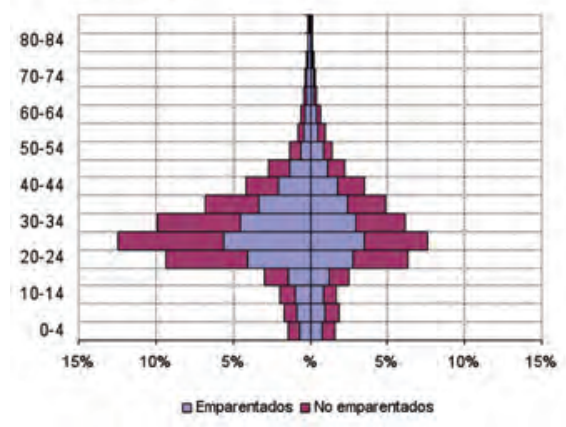

Españoles

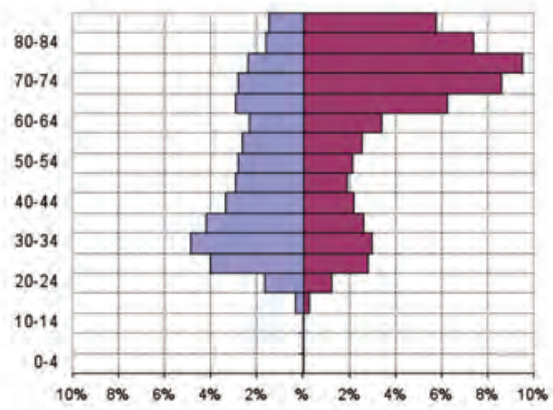

Españoles

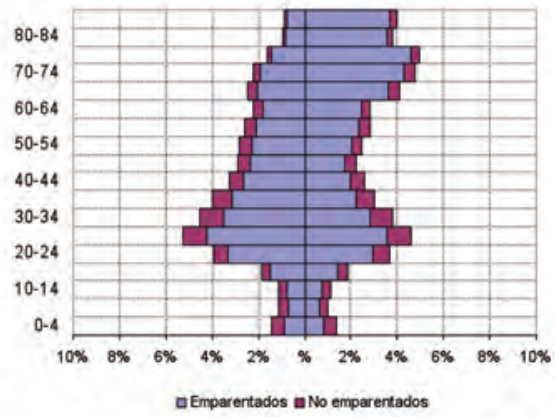

Gráfico 7. Pirámides de población que forman parte de hogares sin núcleo y de hogares unipersonales por nacionalidad, españoles y extranjeros (2001). Fuente: Censo de población y vivienda, 2001, con datos del INE. Elaboración propia.

\section{De la estructura a la situación económica del hogar}

Para finalizar este trabajo, nos aproximamos a la situación económica desde la perspectiva del hogar. Para ello, reproduciremos el ejercicio realizado por Luis Garrido y Luis Toharia (2004) mediante datos de la Encuesta de población activa de los tres primeros trimestres de 2003, para determinar la situación económica de las personas de distintas agrupaciones, aunque nosotros lo hemos llevado a cabo con los datos censales y con agregaciones diferentes. Se ha analizado la situación para hombres y mujeres de nacionalidad española y extranjera y para las nacionalidades previamente seleccionadas, habiendo definido tres tipos de situaciones en los hogares que, como mínimo, presentaban una persona activa: 1) cuando todos sus miembros están ocupados; 2) cuando conviven ocupados y parados, y 3) cuando todos se declaran en paro. En el gráfico 8, se representa la distribución porcentual de personas de cada grupo agregado por sexo que 
vive en cada uno de los tres tipos predefinidos. En los resultados obtenidos por los citados autores, llamaba la atención la mala clasificación de los latinoamericanos en comparación con las restantes agrupaciones continentales para los hogares donde todos estaban en paro, que concordaba con otros análisis sobre la relación con la actividad, esta vez a nivel estrictamente individual, realizados también con datos censales (Domingo y Martínez, 2006), y que se relacionaban, grosso modo, con el tiempo de residencia de los individuos en España y, por lo tanto, una vez más, con el impacto de los flujos más recientes.

Como era de suponer, la comparación entre los grandes agregados para españoles y extranjeros muestra una situación algo peor para los extranjeros. Más de las tres cuartas partes de los españoles residen en hogares donde todos sus miembros activos están ocupados $(76,2 \%)$, mientras que, entre los extranjeros, ese porcentaje se queda en el 66,5\%. La gran diferencia se encuentra en los porcentajes de las personas que forman parte de hogares donde conviven personas ocupadas y personas en paro, con más de 10 puntos porcentuales los extranjeros por encima del $17,8 \%$ de los españoles que se encuentran en esta situación, y con una mínima diferencia para el porcentaje de personas que viven en hogares donde todos sus miembros están en paro, del 6\% para los españoles y del 6,4\% para los extranjeros.

En el gráfico 8 , se han representado los porcentajes para hombres y mujeres de las diferentes agregaciones. Las diferencias según el sexo, en detrimento de los extranjeros, se mantienen con un reparto casi paralelo. Pero al tener en cuenta la variedad estrictamente nacional para hombres y mujeres, estas diferencias son muy sobresalientes, y nos encontramos con algunas sorpresas. En primer lugar, destaca que sea precisamente el Reino Unido, como representante más numeroso de los países de la Unión Europea, el que alcance una mayor proporción de personas que viven en hogares donde todos sus miembros están en el paro, con un $9,5 \%$ para los hombres y un 9,7\% para las mujeres, las cuales tan sólo son superadas por las senegalesas (con un 12,1\%). Aunque ello pueda ser debido al tamaño más reducido de los hogares británicos, también podríamos interpretar este dato como una discriminación positiva, en el sentido de suponer que pueden permitírselo, que entre todo el resto de nacionalidades es la única cuyos individuos pueden permitirse vivir un cierto período en el paro en espera de lograr una ocupación acorde con sus expectativas y su formación.

En segundo lugar, esa situación, sea cual sea el porcentaje obtenido para cada nacionalidad, es sistemáticamente más elevada en el caso de las mujeres que en el de los hombres, al mismo tiempo que las distancias más elevadas entre los porcentajes masculinos y femeninos se dan precisamente para aquellas nacionalidades donde menor es la participación en la actividad de las mujeres, como por ejemplo Senegal (12,1\%), Pakistán (9,7\%) o Marruecos (8,2\%). En este caso, deberíamos discriminar entre la declaración de desocupación y la intención real de ocuparse, aunque todos los demás miembros de la familia se encuentren en paro en el momento censal (recordemos que también son éstas las mujeres que menos probabilidad tienen de vivir solas, únicamente un $4,5 \%$ de las senegalesas vive sola, un 3,6\% de las marroquíes y un 1,2\% de las 

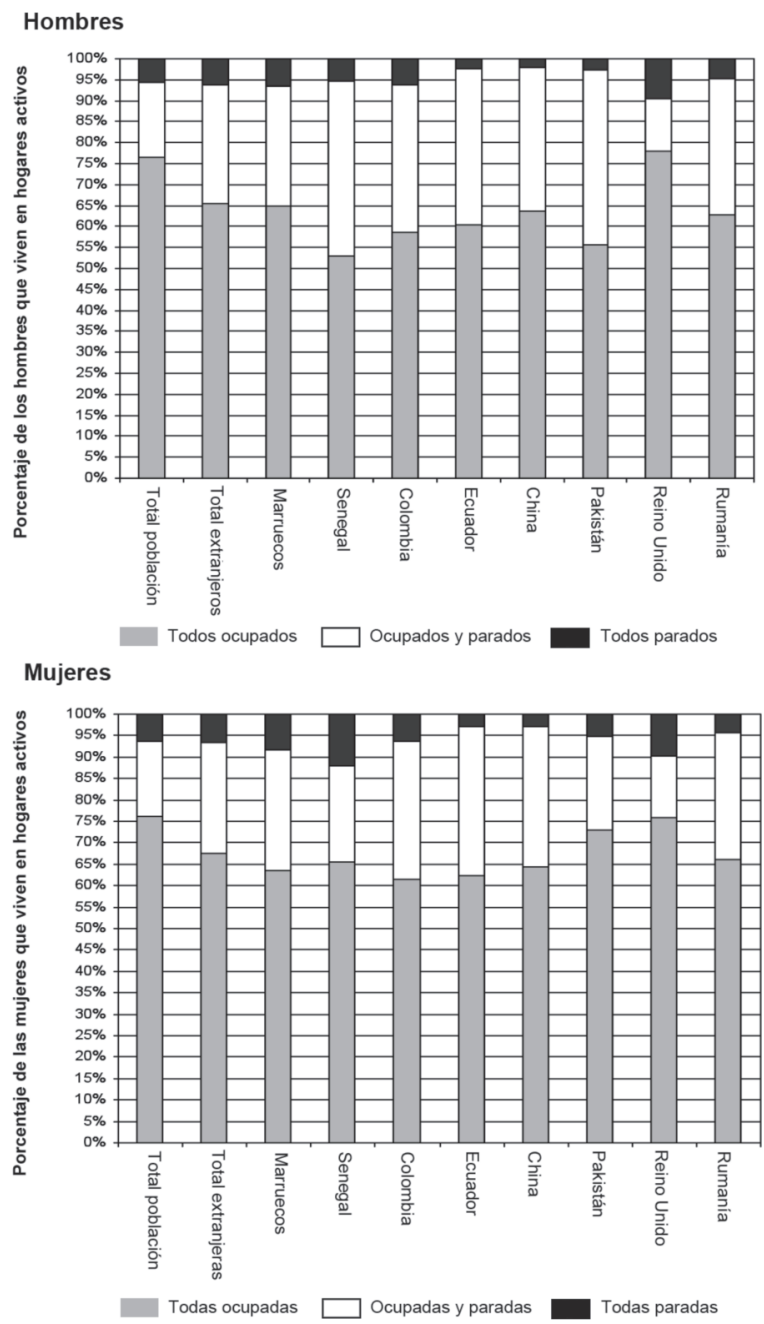

Gráfico 8. Situación de ocupación por hogar de las personas por sexo, total y extranjeros, y selección de nacionalidades (2001). Fuente: Censo de población y vivienda, 2001, con datos del INE. Elaboración propia.

pakistaníes, y no superan en ninguno de los casos el 3\% de hogares monoparentales de madre). Por último, podríamos considerar los impedimentos legales a la ocupación de las mujeres que llegaron como reagrupadas durante el año posterior a su llegada, que también son mayoritarias en estos tres colectivos en comparación con otros. También hay que notar que las mujeres de estas mismas nacionalidades, junto con las británicas y las españolas, son las que registran mayores porcentajes de estar viviendo en hogares donde todos los 
miembros están ocupados. Entre los hombres, y a excepción de los mencionados británicos, marroquíes y colombianos son los que se encuentran en peor posición. Además de volver a considerar el sesgo que el tamaño del hogar puede introducir en la probabilidad de que al menos uno de los miembros se encuentre en paro, las hipótesis sobre este resultado deben ser diferentes, ya que si los colombianos, en 2001, constituían una migración relativamente reciente, reagrupada en parte y con alta irregularidad, los marroquíes contaban con una proporción de población con un mayor tiempo de residencia, cuyos malos resultados pueden estar apuntando a una discriminación dirigida al colectivo magrebí (Solé y Parella, 2003; Izquierdo Escribano, 2004). El resto incluso presenta porcentajes menores al de los españoles en la misma situación, que llegan a ser del 5,8\%, con valores que oscilan entre el 5,4\% de los senegaleses activos y tan sólo el $2 \%$ de los chinos.

En el extremo opuesto, el de personas que habitan hogares donde todos sus miembros están ocupados, la situación más desventajosa la encontramos para los senegaleses y los pakistaníes, donde el porcentaje se sitúa por debajo del $60 \%$, mientras que en las mujeres siempre se supera ese umbral. Las peor situadas son las colombianas $(61,5 \%)$ y las ecuatorianas $(62,4 \%)$, que, como contrapunto, son las que mayor porcentaje de personas tienen conviviendo en hogares donde hay ocupados y parados.

\section{Las estructuras del hogar y el proceso migratorio}

La imagen que hemos extraído de los hogares a través del censo de 2001 correspondía al modelo de unos hogares impactados por flujos muy recientes y crecientes, de ahí la preponderancia de los compuestos por personas que no formaban núcleo familiar, así como de las formas complejas del hogar. Esa peculiar estructura se correspondía claramente con situaciones de sobreocupación. También hemos visto como, a pesar de la sobrerrepresentación de los hogares sin núcleo, especialmente en los recién llegados, los vínculos familiares eran preponderantes en todas las nacionalidades, fueran estos de filiación o de alianza. El proceso migratorio (singularmente el año de llegada) prima sobre cualquier otra característica del extranjero para explicar la estructura del hogar, por encima de las diferencias culturales o de organización familiar de cada uno de ellos. Aunque limitados por la lente censal, es de suponer que lo específico de cada sistema de parentesco debe reflejarse en el tipo de familiar al que se moviliza en el proceso migratorio, más allá del propio núcleo, aunque aquí deberíamos recordar que la legislación española, mediante la reagrupación, acabará favoreciendo también la nuclearidad de las corrientes migratorias. La categorización estadística y la legislación coinciden en favorecer la nuclearidad, incluso podemos sospechar que inducen al migrado a reproducir o a fingir esa nuclearidad privilegiada en el sistema español. En todo caso, lo que sí es particular es el papel de hombres y mujeres en las diferentes estrategias migratorias, que inevitablemente conformará también la estructura del hogar. En ese sentido, la polaridad es muy 
acusada: entre los migrantes latinoamericanos la mujer aparece como pionera, mientras que para ciertas nacionalidades, como los marroquíes o los pakistaníes, es el hombre quien suele anteceder en los movimientos migratorios.

Aunque en este trabajo no se ha abordado, esa diferencia radical que implica los papeles de género, obviamente apunta a situaciones muy distintas dentro del hogar, parcialmente reflejadas en el censo por la jefatura del mismo, la persona principal. Papeles de género que el propio proceso migratorio altera, no sólo en una dirección, ya que cada fase implica una asunción o renegociación de esos papeles, remarcable entre las corrientes feminizadas, pero también a considerar entre las que no lo están (Martín Díaz, 2008).

La unidad doméstica es fundamental para comprender no sólo las pautas migratorias, sino también las condiciones de vida de las personas inmigradas. Recordemos que, en 2001, la situación de paro entre los extranjeros parece traducir por lo común una llegada reciente, achacable, en el caso de ecuatorianos y colombianos, a una reagrupación por parte de sus cónyuges como respuesta a la crisis económica de sus propios países. En todo caso, la excelente coyuntura económica era entonces capaz de absorber esos flujos llegados por causas exógenas a la demanda de la mano de obra del mercado de trabajo, a la vez que esos flujos seguirían revertiendo en el crecimiento económico.

La actual perspectiva de una recesión económica nos empuja a preguntarnos cuál puede ser la situación en los próximos años. La primera previsión sería el freno de la expansión de la dinámica familiar de los extranjeros, que debería llevar a una mayor creación de hogares y a un avance aún más significativo de los formados por parejas simples, en convergencia con el total español. Pero, una vez más, la perspectiva de género es fundamental. Nuestra hipótesis es que, teniendo en cuenta que la construcción es uno de los sectores que más han acusado ese impacto, no está de más prever que los hogares más vulnerables son aquéllos donde las mujeres aparecen como inactivas y cuyos hombres trabajan en ese sector (tenemos en mente a los marroquíes, por ejemplo). Mientras que los hogares donde las mujeres han sido las pioneras del movimiento migratorio, como ecuatorianas y colombianas entonces, y bolivianas ahora, la probabilidad de que todos los miembros de la familia se encuentren en paro es menor, pero la fricción entre los papeles en el seno de la pareja aumentará de forma significativa. No sólo ellas han sido pioneras (y reagrupadoras), sino que también ven reafirmada su posición de sustentadoras del hogar, en contra del papel subsidiario que el reparto de género les atribuye, y de la situación discriminatoria que su triple rol como mujer, inmigrante y trabajadora pudiera conllevar (Parella, 2003).

Además, es fundamental pensar en el papel de la reagrupación familiar, que desde entonces se ha multiplicado, no sólo por lo que se refiere al incremento de la presencia de menores, muchos ya nacidos en España, sino también en la reagrupación de personas mayores, también conectada con las diferencias de género. Hay que recordar que aquellas mujeres inmigradas ocupadas, al reagrupar a sus esposos e hijos y verse abocadas a retomar el trabajo domés- 
tico dentro de su propio hogar, han recurrido a la reagrupación de madres (las abuelas) para que se hagan cargo de, por lo menos, parte de ese trabajo. De hecho, están replicando la razón por la cual las mujeres autóctonas han podido también acceder más rápidamente al mercado de trabajo (el recurso a las generaciones mayores), y cuando ello no es posible, las inmigradas extranjeras, al igual que las autóctonas, deberán recurrir a la externalización: otras compatriotas o inmigradas que asuman el cuidado de sus hijos mientras ellas trabajan, o sus maridos en paro. La gran diferencia está marcada por las condiciones muchísimo más precarias en las que se encontrarán.

\section{Referencias bibliográficas}

APARICIO, Rosa y TORnos, Andrés (2005). Las redes sociales de los inmigrantes extranjeros en España: Un estudio sobre el terreno. Madrid. Observatorio Permanente de la Inmigración. Ministerio de Trabajo y Asuntos Sociales.

BAYONA, Jordi (2007). «La estructura del hogar como reflejo de una primera etapa del proceso migratorio: el caso de la ciudad de Barcelona». Papeles de Geografía, 4546, 5-26.

BLEDSOE, Caroline (2006). «The demography of family reunification: from circulation to substitution in Gambian Spain». Max Planck Institut for Demographic Research Working Paper 1006-053, 1-31.

CAmarero Rioja, Luis y García Borrego, Iñaki (2004). «Los paisajes familiares de la inmigración». RES, 4, 173-198.

Cortina, Clara; EsTeVE, Albert y Domingo, Andreu (2006). «Crecimiento y singularidades demográficas de los matrimonios de extranjeros en España». Migraciones, $20,75-105$.

- (2008). «Marriage patterns of foreign born population in a new country of inmigration: the case of Spain». International Migration Review, 42 (4), invierno.

DELGADO, Margarita y ZAMORA, Francisco (2004). «Españolas y extranjeras: su aportación a la fecundidad de España». Economistas, 99, 88-97.

Devolder, Daniel; Domingo, Andreu y GarCía, Joan (2003). «Fecundidad y reagrupación familiar de la población de nacionalidad extranjera en la Comunidad de Madrid». Papers de Demografia, 224.

DomingO, Andreu (2006). «Tras la retórica de la hispanidad: la migración latinoamericana en España entre la complementariedad y la exclusión». En: CANALES, Alejandro I. (ed.). Panorama actual de las migraciones en América Latina. Guadalajara (México): Asociación Latinoamericana de Población. Universidad de Guadalajara, $21-44$.

Domingo, Andreu; BAYONA, Jordi y BRANCós, Inés (2002). Migracions internacionals i població jove de nacionalitat estrangera. Barcelona: Secretaria General de Joventut. Generalitat de Catalunya.

- (2002). «Estrategias migratorias y estructuras del hogar en Cataluña, 1996». Papers de Demografia, 202. 24 p.

DOMINGO, Andreu y MARTíNeZ, Rosana (2006). «La población latinoamericana censada en España en 2001: un retrato sociodemográfico». Notas de Población, 81, 99-128.

Domingo, Andreu y Parnau, Maria (2007). «Familia y estructura del hogar de la población de nacionalidad extranjera en España, 2001\%. Papers de Demografia, 279. 
FERNÁNDEZ CORDÓN, Juan Antonio (2006). «Natalidad y fecundidad en las regiones españolas». En: Fernández Cordón, J.A. y LeAl Maldonado, Jesús (coord.). Análisis territorial de la demografía española, 2006. Madrid: Fundación Abril Martorell, 181-208.

GARRIDO, Luis y TOHARIA, Luis (2004). «La situación laboral de los españoles y de los extranjeros según la Encuesta de Población Activa». Economistas, 99, 74-86.

IZQuierdo Escribano, Antonio; LÓPEZ de Lera, Diego y Martínez BujÁn, Raquel (2002). «Los preferidos del siglo XXI: la inmigración latinoamericana en España». Actas del 3r Congreso de la Inmigración en España, 2. Granada, 237-250.

IZQUiERdo ESCRIBANO, Antonio y LÓPEZ DE LERA, Diego (2003). «Natalidad y nacionalidad: efectos de las tasas de natalidad de poblaciones inmigrantes». En: VVAA. La natalidad en España: Situación y estrategias socioeconómicas. Madrid: Ministerio de la Presidencia. Universidad Menéndez y Pelayo.

IZQUIERDO ESCRIBANO, Antonio (2004). «Los preferidos frente a los extranjeros permanentes: la inmigración marroquí en los inicios del siglo XXI». En: LÓPEZ GARCíA, Bernabé y BERRIANE, Mohamed (dir.). Atlas de la inmigración marroqui en España. Madrid: Taller de Estudios Internacionales Mediterráneos. Universidad Autónoma de Madrid.

IZQUIERDO EsCRIBANO, Antonio (dir.) (2006). Demografía de los extranjeros: incidencia en el crecimiento de la población. Madrid: Fundación BBVA.

Jasso, Guillermina y RosenzWeIG, Mark R. (1986). «Family reunification and the immigration multiplier: US immigration law, origin-country conditions, and the reproduction of immigrants». Demography, 3, 23, agosto, 291-311.

KING, Miriam y Preston, Samuel H. (1990). "Who Lives with whom? Individual versus household measures». Journal of Family History, 15 (2), 117-132.

LASLETT, Petter (1972). "Introduction: The history of the family». En: Household and family in past time. Cambridge: Cambridge University Press, 1-86.

MARTín DíAZ, Emma (2008). "El impacto del género en las migraciones de la globalización: mujeres, trabajos y relaciones interculturales». Comunicación presentada en el $X$ Congreso Internacional de Geocrítica. Barcelona.

Parella, Sonia (2003). Mujer, inmigrante y trabajadora: la triple discriminación. Rubí: Anthropos.

Pascual DE SAns, Àngels (dir.) (2007). Redes sociales de apoyo: La inserción de la población extranjera. Madrid: Fundación BBVA.

PORTES, Alejandro y BÖRÓCZ, Jozsef (1982). «Inmigración contemporánea: perspectivas teóricas sobre sus determinantes y modos de acceso». Alfoz, 91/92, 20-33.

RECAÑO, Joaquín (2002). «La movilidad geográfica de los extranjeros en España: un fenómeno emergente». Cuadernos de Geografía, 72, 135-156.

- (2004). «Las migraciones internas y la distribución espacial en España». En: LEAL Maldonado, Jesús (coord.). Informe sobre la situación demográfica en España. Madrid: Fundación Abril Martorell, 201-218.

Requena y Díez de Revenga, Miguel (2001). «Los hogares en Europa, con especial referencia a España». En: GARRIDO MEdina, Luis y TOHARIA CORTÉs, Luis. Condiciones de vida en España y en Europa. Madrid: Instituto Nacional de Estadística, 31-74.

- (2005). Características de los hogares y familias de la comunidad de Madrid según el censo de 2001. Madrid: Instituto de Estadística. Comunidad de Madrid. Estudios y Análisis. 
- (2006). «Los hogares españoles en la perspectiva regional». En: FERNÁNDEZ Cordón, J.A. y Leal Maldonado, Jesús (coord.). Análisis territorial de la demografía española, 2006. Madrid: Fundación Abril Martorell, 209-222.

Rey PovedA, Alberto del y ORTEGa OsonA, José Antonio (2007). «La reproducción de la población en las provincias españolas, 1975-2005. Efectos de la migración y la fecundidad en el reemplazo de los nacimientos». Comunicación presentada en el IX Congreso Español de Sociología, organizado por la Federación Española de Sociología (FES), Barcelona, 13-15 de septiembre.

RodrígueZ, Dan (2004). «Inmigración y mestizaje hoy. Formación de matrimonios y familias transnacionales de inmigrantes en Cataluña». Migraciones, 16, 77-120.

- (2006). «Mixed marriages and transnacional families in the intercultural context: A case study of African Spanish couples in Catalonia». Journal of Ethnic and Migration Studies, 32 (3), 403-433.

Roig Vila, Marta y CASTRO MARTÍN, Teresa (2007). «La fécondité des étrangères dans un pays d'immigration récente: le cas d'Espagne». Population, 62, 3, 419-450.

SALT, John (2005). Types of migration in Europe: implications and policy concerns. European Population Conference, 2005. Demographic Challenges for Social Cohesion. Estrasburgo: Council of Europe.

Solé, Carlota y PARElla, Sonia (2003). «The labour market and racial discrimination in Spain». Journal of Ethnic and Migration Studies, 29, 1, 121-140. 